\title{
Tallemant des Réaux, Historiettes
}

\section{Monica Pavesio}

\section{(2) OpenEdition}

\section{Journals}

\section{Edizione digitale}

URL: http://journals.openedition.org/studifrancesi/2134

DOI: 10.4000/studifrancesi.2134

ISSN: 2421-5856

\section{Editore}

Rosenberg \& Sellier

\section{Edizione cartacea}

Data di pubblicazione: 1 aprile 2014

Paginazione: 140

ISSN: 0039-2944

\section{Notizia bibliografica digitale}

Monica Pavesio, «Tallemant des Réaux, Historiettes », Studi Francesi [Online], 172 (LVIII | I) | 2014,

online dal 01 avril 2014, consultato il 18 septembre 2020. URL : http://journals.openedition.org/ studifrancesi/2134; DOI : https://doi.org/10.4000/studifrancesi.2134

\section{Questo documento è stato generato automaticamente il 18 settembre 2020.}

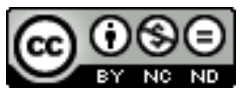

Studi Francesi è distribuita con Licenza Creative Commons Attribuzione - Non commerciale - Non opere derivate 4.0 Internazionale. 


\title{
Tallemant des Réaux, Historiettes
}

\author{
Monica Pavesio
}

\section{NOTIZIA}

TALLEMANT DES RÉAUX, Historiettes, Choix et présentation de M. JEANNERET, établissement du texte d'A. ADAM, notes d'A. ADAM e de M. JEANNERET, Paris, Gallimard, 2013, pp. 914.

1 Le edizioni Gallimard ripubblicano le Historiettes di Tallemant des Réaux, riprendendo una piccola parte (circa un terzo) del testo dell'edizione completa in due volumi, stampata da Gallimard nel 1960, a cura di Antoine Adam.

2 La nuova edizione modernizzata presenta, in aggiunta, una ricca introduzione di M. Jeanneret, un apparato di note sulla lingua di Tallemant e un dossier bibliografico e linguistico.

3 La scelta di pubblicare solo una parte delle Historiettes rende fruibili al grande pubblico queste storielle scandalose sulla vita parigina della prima metà del XVII secolo, uscite dalla clandestinità solo due secoli dopo la loro redazione. Brevi ritratti di personaggi famosi, storielle comiche, corti saggi, le Historiettes conservano ancora oggi il loro fascino, svelando un XVII secolo truculento e debosciato, sensuale e profano, molto diverso da quello tramandatoci dalla critica. 